\title{
Living with Juvenile Idiopathic Arthritis: Parent and Physician Perspectives
}

Shelly Heath-Watson · Sangeeta Sule

Received: January 22, 2018 / Published online: February 26, 2018

(C) The Author(s) 2018. This article is an open access publication

\begin{abstract}
This article, co-authored by a parent of a child with juvenile idiopathic arthritis (JIA) and his pediatric rheumatologist, discusses the parent's experience of having a child with JIA from diagnosis through living day-to-day with the disease.
\end{abstract}

Keywords: Injection; Juvenile idiopathic arthritis; Quality of life

\section{PARENT'S EXPERIENCE}

The first words that came to my mouth when my 5-year-old son was diagnosed with juvenile idiopathic arthritis were "Thank God." I was grateful for a name. The elusive condition that

Enhanced content To view enhanced content for this article go to https://doi.org/10.6084/m9.figshare. 5853888 .

S. Heath-Watson

Silver Spring, Maryland, USA

S. Sule $(\bowtie)$

Department of Pediatrics, Pediatric Rheumatology, Johns Hopkins University, Baltimore, MD, USA e-mail: ssule@jhmi.edu made my son's knees swell like baseballs and reduced him to scooting on his backside instead of walking, finally had a name: polyarticular juvenile idiopathic arthritis-JIA. Arthritis is a complicated disease.

My husband and I had never heard of a child with arthritis prior to Elijah's diagnosis. We had only known it to be a disease of the aging or of retired athletes suffering from years of hardwood wear and tear. Our son's condition perplexed more than a few practitioners, as we were told on more than one occasion that the aching and swelling were caused by growing pains; others said it was caused by over-exertion from his time on the playground. We were determined to find answers, and our pursuit for resolution and our journey toward relief had our path cross with Dr. Sangeeta Sule at Johns Hopkins Children's Center.

My son's initial intervention was a nonsteroidal anti-inflammatory drug. While this did relieve some of his joint pain, it caused tremendous stomach distress. I vividly remember one night in particular-my son was exhausted from vomiting and dry heaving; I was wearied from not being able to do more for him. I was sitting on the tub when my then 7-year-old grabbed my face in his hands and said: "Mommy, just tell me if this is how it's gonna be. I can do it, but I just need to know." Arthritis is an emotional disease.

This episode was soon followed by my son's first experience with immunosuppressive drug 
therapy and weekly injections. While it was clear the current course of action was not adequately managing his condition, the move to injections was devastating. It felt so drastic. To me it signified an escalation in the seriousness and permanence of the disease and its impact on my son's life. As his mom and lead injector, the longitudinal study data on the safety and effectiveness of the drug did little to allay my concerns. The long- and short-term impact of the shots on my son's physiological and psychological health stayed top of mind for me throughout the duration of his treatment. I read the label on the medicine bottle, which warned me about the hazards should the contents come into contact with my skin-the same contents I was injecting into my son's body. Arthritis is a scary disease.

My son was on injections for a little over 2 years this particular cycle. The process of administering a shot is simple but in no way easy. I learned many lessons on how to best emotionally support him and position me to be a calm, positive, and encouraging force for him. The ritual started days before the injection.

Despite his health challenges, I always wanted to be sure Elijah knew that he had many things for which to be thankful. I introduced "bum" and "best" to our family's daily dinner routine. Each of us went around the table and shared something about the day that didn't go well-the bum. Discussion ensued. We each then shared what was great about the day-the best. You didn't have to have a bum-but everyone had to share a best (even if the best was just "okay"). This practice kept us ever seeking and speaking of positive things. "Shot day" came with its own set of rituals.

I bought a clear plastic storage container with a handle in which I stored everything I needed for the injections. I kept the items in the order in which I used them: alcohol swabs, gauze pads, syringes, medicine, band-aids, and stickers. Not having to think about gathering the items together helped to minimize the stress for me. My son hated the injections, and it wasn't long before I did too. I typed and taped a supporting Scripture on the top of the container, as it was the first and last thing I saw before and after the injections. Some of my son's shot days were uneventful; others were filled with anxiety and fear. To ease his nerves (and mine), we prayed as I gave him the shot, most times with my father (better known as Pop Pop) on the phone from New York. My family created a "treat bag" for my son-there was something new added to it every week to love on and celebrate him when the shot was completed. Pop Pop often sent down surprises for the treat bag. Next, we braced for the nausea and lethargy that permeated the days following the injection. Everyone worked to fill those hours with "fun distractions" to help Elijah focus on things other than his discomfort. Arthritis is a family disease.

It's been more than 10 years since Elijah's diagnosis. He is now taking a weekly injectable biologic that he self-administers (while I pray). He no longer has a treat bag but contributes to the one sponsored by Johns Hopkins each time he has a rheumatology appointment. The relationship Dr. Sule has nurtured with him has Elijah very knowledgeable about his disease; he prepares questions in advance of his appointments; he knows all of his medications (which at its height was more than seven pills a day); and he confidently selfmanages his activities. Elijah greatly appreciates Dr. Sule's genuine interest in who he is as a young man, his habits, and his hobbies. Arthritis is a multi-faceted disease.

As a parent, there is so much more to managing arthritis than monitoring joint pain and swelling and supervising injections. Arthritis demands communication-consistent and compassionate communication with your child; inquisitive communication with members of the health care team; informative communication with teachers, coaches, and administrators in the school system; and instructional communication with family members and friends. Arthritis is a community disease.

While it does take a village to provide all of the support needed to create a healthy and safe environment for the child with arthritis, as parents, physicians, teachers, family, and friends, we must never forget several irrefutable truths about this chronic condition. 
Arthritis is a painful disease. Arthritis is a lifealtering disease. Arthritis is an isolating disease.

The courage and optimism with which my son chooses to approach each and every day never ceases to amaze and inspire me. Elijah chooses to find the compromise instead of complaining; he is strategic in how and when he expends his energy; he accepts that there are times when he has to do things differently and there are times when he must do nothing at all. He is a study in living life from a place of gratitude-poignantly sharing life lessons (always with actions, never with words) with those of us blessed to be a part of his village.

\section{PHYSICIAN'S PERSPECTIVE}

As told from the parent's perspective, juvenile idiopathic arthritis (JIA) can cause so much more than arthritis. The disease, medications, doctor visits, and frequent laboratory testing can have a significant impact on the psyche of the child with arthritis. Social support, including strong family involvement, can significantly improve outcomes in JIA.

JIA is the most common chronic rheumatic disease in childhood. It is a complex inflammatory disease with multifactorial pathogenesis including genetic predisposition and environmental factors leading to chronic inflammatory response. The resulting autoimmune disease manifests as synovial tissue inflammation, leading to chronic arthritis, which can impact physical function, attendance at school, and pain levels.

Given these challenges of JIA, it is not surprising that children with JIA are at risk for depression and separation anxiety [1]. In the clinic, I often see children withdraw from friends and school activities after being diagnosed. Steroids can change the way children look-with weight gain, moon faces, and swelling-while disease-modifying therapies may increase the risk of infections, further scaring families from normal social interactions.

Family and caregiver engagement in clinic makes a significant difference to children with JIA [2]. In the clinic, we have multiple visits with the family or caregiver to discuss medications or treatment options. We have nursing visits to show the family how to administer the injections. I will never forget the first time I saw a mother being shown how to give their 4-year-old a shot of methotrexate. Tears were streaming down the mother's face, but she did it. Two months later, the child came running into the clinic-arthritis in remission.

I feel very fortunate to be a pediatric rheumatologist. I have been able to watch Elijah, the young man in the accompanying parent piece, grow up into an incredible person. He is active, plays the drums in school, has many friends, and is an amazing person. As his doctor, I saw at every visit how involved his mother and family were with his care. They were always supportive, but at the same time, fostered Elijah's independence. This delicate balance of allowing children to hurt and cry when their arthritis is active, but still encouraging them to play and be themselves is very difficult to achieve. I am in awe of Elijah and his family and every child who faces arthritis but never lets it hold them back.

\section{ACKNOWLEDGEMENTS}

Funding. No funding or sponsorship was received for this study or publication of this article.

Authorship. All named authors meet the International Committee of Medical Journal Editors (ICMJE) criteria for authorship for this article, take responsibility for the integrity of the work as a whole, and have given their approval for this version to be published.

Disclosures. Shelly Heath-Watson and Sangeeta Sule have nothing to disclose.

Compliance with Ethics Guidelines. This article does not contain any new studies with human or animal subjects performed by any of the authors.

Peer Review. Please note, contrary to the journal's standard double-blind peer-review 
process, as a commentary, this article underwent review by a member of the journal's Editorial Board.

Open Access. This article is distributed under the terms of the Creative Commons Attribution-NonCommercial 4.0 International License (http://creativecommons.org/licenses/ by-nc/4.0/), which permits any noncommercial use, distribution, and reproduction in any medium, provided you give appropriate credit to the original author(s) and the source, provide a link to the Creative Commons license, and indicate if changes were made.

\section{REFERENCES}

1. David J, Cooper C, Hickey L, et al. The functional and psychological outcomes of juvenile chronic arthritis in young adulthood. $\mathrm{Br} \mathrm{J}$ Rheumatol. 1994;33:876-81.

2. Knafl K, Leeman J, Havill N, et al. The contribution of parent and family variables to the well-being of youth with arthritis. J Fam Nurs. 2015;21:579-616. 